\title{
Effect of Particle Characteristics and Temperature on Shear Yield Stress of Magnetorheological Fluid
}

\author{
Xiangfan $\mathrm{Wu}^{1}$, Xingming Xiao ${ }^{1 *}$, Zuzhi Tian ${ }^{1,2}$, Fei Chen ${ }^{1}$, and Wang Jian ${ }^{1}$ \\ ${ }^{1}$ College of Mechanical and Electrical Engineering, China University of Mining and Technology, Xuzhou, China \\ ${ }^{2}$ Xuzhou Wuyang Technology Co., Ltd, Xuzhou, China
}

(Received 11 March 2016, Received in final form 20 May 2016, Accepted 25 May 2016)

\begin{abstract}
Aiming to improve the shear yield stress of magnetorheological fluid, magnetorheological fluids with different particle characteristics are prepared, and the influence rules of particle mass fraction, particle size, nanoparticles content and application temperature on shear yield stress are investigated. Experimental results indicate that shear yield stress increases approximate linearly with the enhancement of particle mass fraction. Particle size and the nanoparticles within $10 \%$ mass fraction can improve the shear yield stress effectively. When the application temperature is higher than $100{ }^{\circ} \mathrm{C}$, the shear yield stress decreases rapidly because of thermal expansion and thermal magnetization effect.
\end{abstract}

Keywords : preparation, shear yield stress, magnetorheological fluid, nanoparticles, temperature

\section{Introduction}

Magnetorheological (MR) fluid is a typical intelligent material that consists of micro-sized soft magnetic particles, additives and nonmagnetic carrier fluid. It behaves attractive rheological characteristics upon the application of external magnetic field and has been widely used in clutches, brakes, dampers and polishing [1-4]. There are some indexes to evaluate the properties of MR fluid, such as, the sedimentation stability, shear yield stress, responding time, application temperature and zero-field viscosity [5-7]. Among them, the shear yield stress is the most important properties and determines the application field of MR fluid, especially in power transmission occasion $[8,9]$.

At present, the shear yield stress of MR fluid is still not very high, for instance, the shear yield stress of MRF132DG prepared by Lord Company (USA) is only $50 \mathrm{kPa}$. Therefore, many researchers investigated the influence factors to improve the yield stress of MR fluid. Tang calculated the static shear yield stress by theoretical analysis method [10]. Ginder analyzed the effect of magnetic saturation $[11,12]$. Han investigated the field-dependent

(C)The Korean Magnetics Society. All rights reserved.

*Corresponding author: Tel: +86-13914876762

Fax:+86-516-83590777, e-mail: tianzuzhi@163.com characteristics of MR fluids containing corroded iron particles [13]. Spaggiari researched the effect of pressure on shear yield stress [14]. Wang and Sahin investigated the effect of temperature on shear yield stress $[15,16]$. As reviewed above, there is still lack of systematic analysis on the effect of the particle characteristics and application temperature. In this paper, in order to obtain the optimum preparation process of MR fluid with high shear yield stress, a series of MR fluids with different particle sizes, particle mass fractions, nanoparticles contents and the application temperatures are prepared respectively to measure their shear yield stresses and magnetic properties, and to research the influence rules of corresponding factors.

\section{Experimental}

\subsection{Materials}

Carbonyl iron particles (CIP) are used as soft magnetic particles of MR fluid due to those high saturation magnetization and small remanence. The particles are spherical and polydisperse, and the average particle diameter is 2.0 $\mu \mathrm{m}, 3.5 \mu \mathrm{m}, 5.0 \mu \mathrm{m}$ and $7.0 \mu \mathrm{m}$ respectively shown in Fig. 1 observed by scanning electron microscopy (SEM).

The volume fraction or mass fraction of particle is an important process parameter of MR fluid, and the volume fraction can be expressed as: 


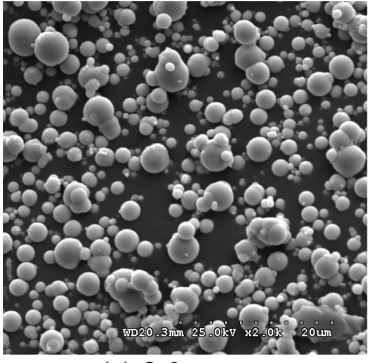

(a) $2.0 \mu \mathrm{m}$

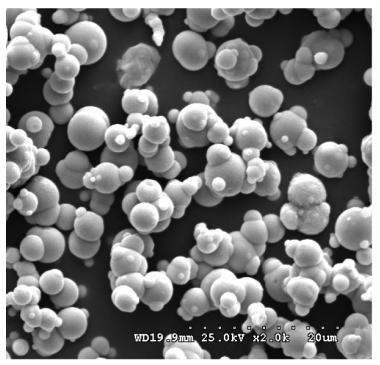

(c) $5.0 \mu \mathrm{m}$

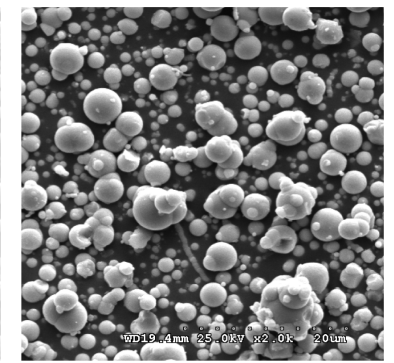

(b) $3.5 \mu \mathrm{m}$

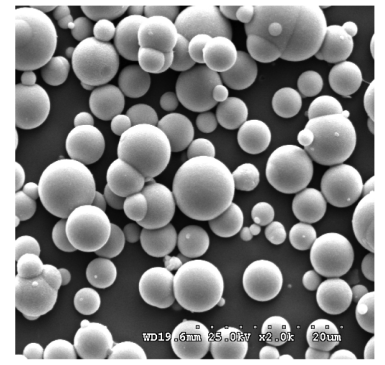

(d) $7.0 \mu \mathrm{m}$
Fig. 1. SEM photo of CIP.

$$
\phi_{p}=\frac{\frac{4}{3} \pi R^{3}}{(2 R+l)^{3}}
$$

Where, $R$ is the radius of particles, $l$ is the distance of adjacent particles surface. When two particles contact with each other, the value of $l$ is zero, the maximum volume fraction of particles is $52.3 \%$, and the corresponding mass fraction is $89.65 \%$ assumed that the particle size is uniform absolutely.

\subsection{Methods}

The shear yield stress of prepared MR fluids can be measured by a self-designed shear yield stress instrument, as shown in Fig. 2. It mainly contains four parts: power source (stepping motor), shear section (MR fluid shear structure), measurement section (torque sensor) and other structures (base, hoisting and oriented structures). The working principle is as follows: when the rotational disk is drove by the stepping motor, MR fluid under a certain magnetic field can transmit a torque, and the torque can be measured by the torque sensor connected with the stationary disk. As the rotation speed is very low, the shear yield stress $\tau_{0}$ can be obtained by the forum: $\tau_{0}=\frac{3 T}{2 \pi R^{3}}$. Where $R$ is the radius of disk, $\tau_{0}$ is fielddependent yield stress, $T$ is the torque.

Magneto-properties of particles or MR fluids which impact on the shear yield stress strongly can be measured by a Vibration Sample Magnetometer (VSM), supplied by

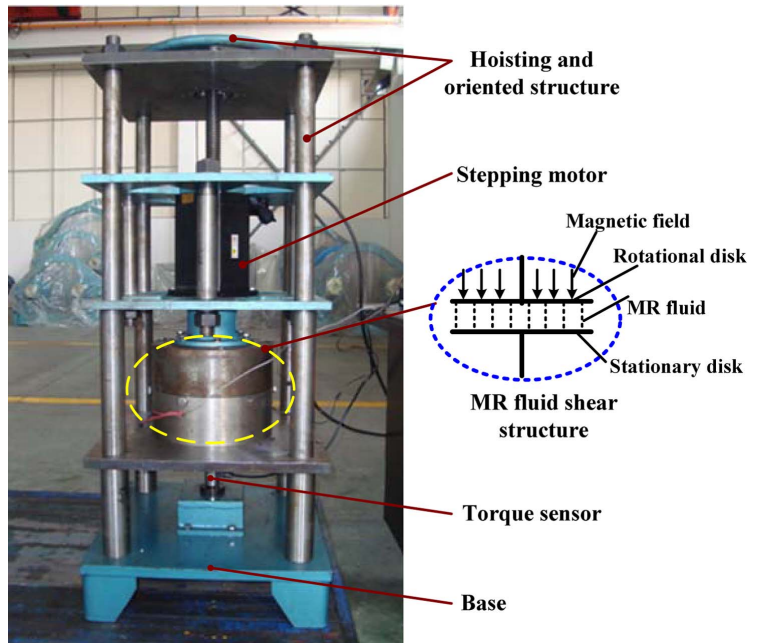

Fig. 2. (Color online) Yield stress measurement device.

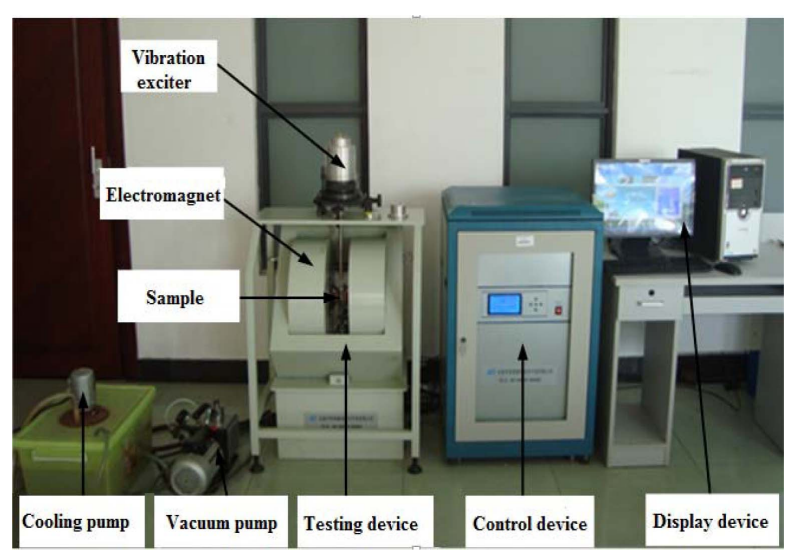

Fig. 3. (Color online) Vibration sample magnetometer (VSM).

Changchun Electromagnet Company (China). The VSM is mainly composed of cooling pump, vacuum pump, testing device, control device, display device, etc, as shown in Fig. 3.

\section{Results and Discussions}

\subsection{Different particle mass fractions}

In this experiment, the $7.0 \mu \mathrm{m}$ diameter particles are used to prepare MR fluids, and the particle mass fraction of MR fluids is $70.2 \%, 66.9 \%$ and $60.4 \%$ respectively. The shear yield stress and magnetization of the prepared MR fluids are measured by yield stress measurement device and vibration sample magnetometer respectively, and the results are presented in Fig. 4. Figure 4(a) shows the effect of mass fraction on the shear yield stress of MR fluid, and Fig. 4(b) shows the influence of mass fraction on magnetization of MR fluid.

As shown in Fig. 4(a), it is indicated that the mass 


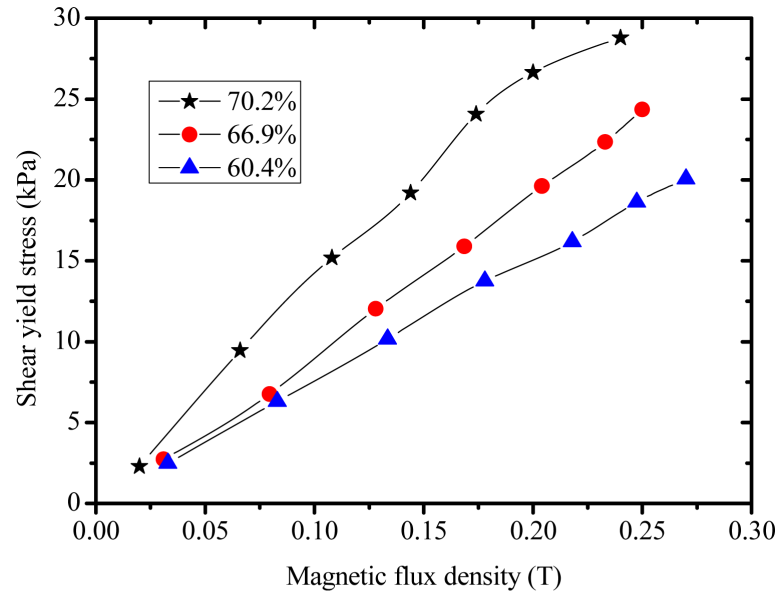

(a) Effect of mass fraction on shear yield stress

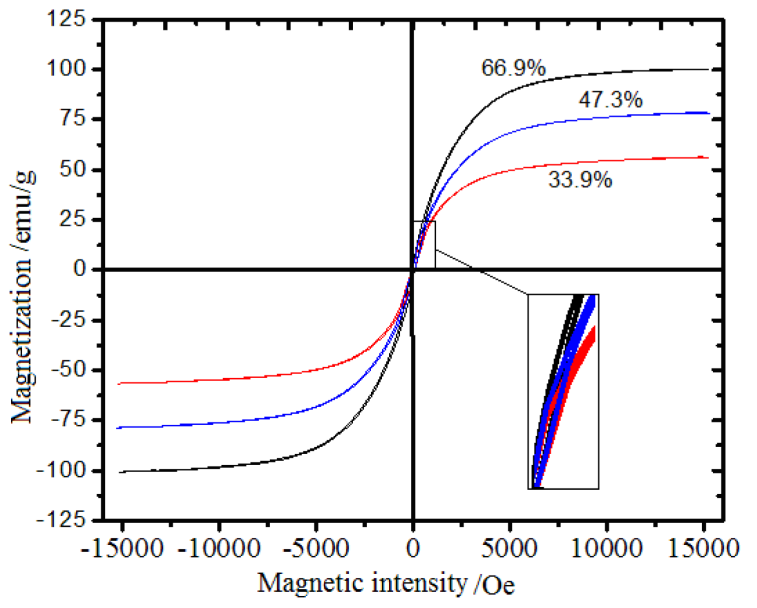

(b) Effect of mass fraction on magnetization of MR fluid

Fig. 4. (Color online) Effect of particle mass fraction.

fraction has an attractive effect on the shear yield stress of MR fluid, and the shear yield stress increases with the enhancement of particle mass fraction. According to the experimental results, the shear yield stress of $70.2 \% \mathrm{MR}$ fluid increases by $78 \%$ than that of $60.4 \%$ as the magnetic flux density is $0.2 \mathrm{~T}$. The reason is that the higher particle mass fraction has stronger magnetization that strongly influences the shear yield stress of MR fluid, as shown in Fig. 4(b). In order to observe the difference clearly, 33.9\% and $47.3 \%$ mass fraction MR fluids are also prepared and the magnetization are measured by the VSM. It is clearly demonstrated that CIP is a high performance soft magnetic material with very low remanence. Moreover, the saturation magnetization is $108 \mathrm{emu} / \mathrm{g}, 78 \mathrm{emu} / \mathrm{g}$ and $56 \mathrm{emu} / \mathrm{g}$ respectively when the mass fraction is $66.9 \%, 47.3 \%$ and $33.9 \%$, a conclusion can be given that the saturation magnetization increases approximate linearly with the mass fraction.

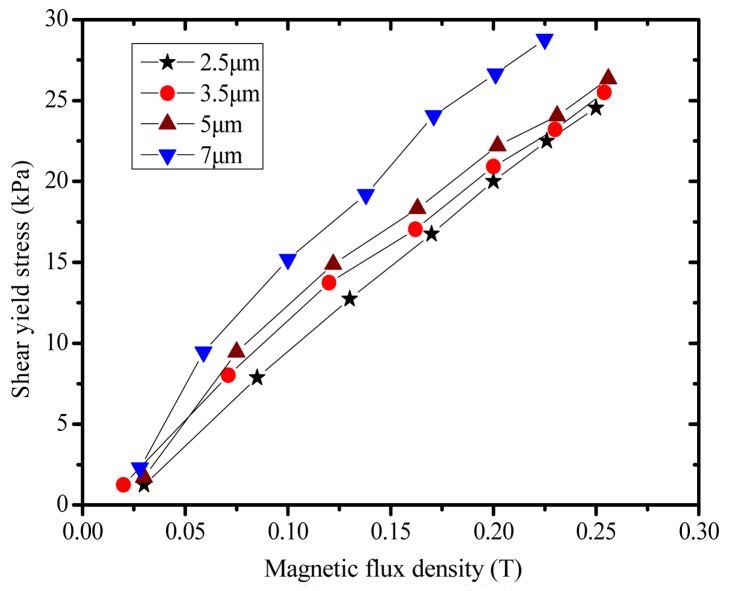

(a) Effect of particle size on shear yield stress

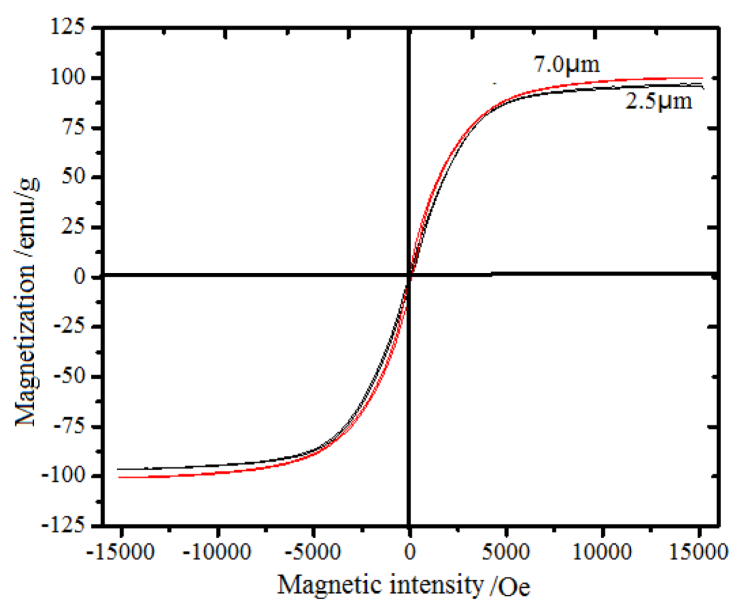

(b) Effect of particle size on magnetization of MR fluid

Fig. 5. (Color online) Effect of particle size.

\subsection{Different particle sizes}

In this experiment, the average diameters of $2.5 \mu \mathrm{m}, 3.5$ $\mu \mathrm{m}, 5.0 \mu \mathrm{m}$ and $7.0 \mu \mathrm{m}$ particles are chosen respectively to prepare MR fluids with the mass fraction $70.2 \%$. The shear yield stress of prepared MR fluids can be obtained as shown in Fig. 5. Figure 5(a) marked the effect of particle size on shear yield stress of MR fluid, and Fig. 5(b) shows the effect of particle size on magnetization of MR fluid, where the particles diameter is $2.5 \mu \mathrm{m}$ and 7 $\mu \mathrm{m}$ respectively.

It is observed that the particle size also has influence on the shear yield stress of MR fluid, and the larger particle size, the greater shear yield stress. When the magnetic flux density is $0.2 \mathrm{~T}$, the shear yield stress of MR fluid with $2.5 \mu \mathrm{m}, 3.5 \mu \mathrm{m}, 5.0 \mu \mathrm{m}$ and $7.0 \mu \mathrm{m}$ particles is $19.999 \mathrm{kPa}, 20.909 \mathrm{kPa}, 22.190 \mathrm{kPa}$ and $24.061 \mathrm{kPa}$ respectively. According to the Fig. 5(b), the saturation magnetization of MR fluid with $7.0 \mu \mathrm{m}$ and $2.5 \mu \mathrm{m}$ is 105 


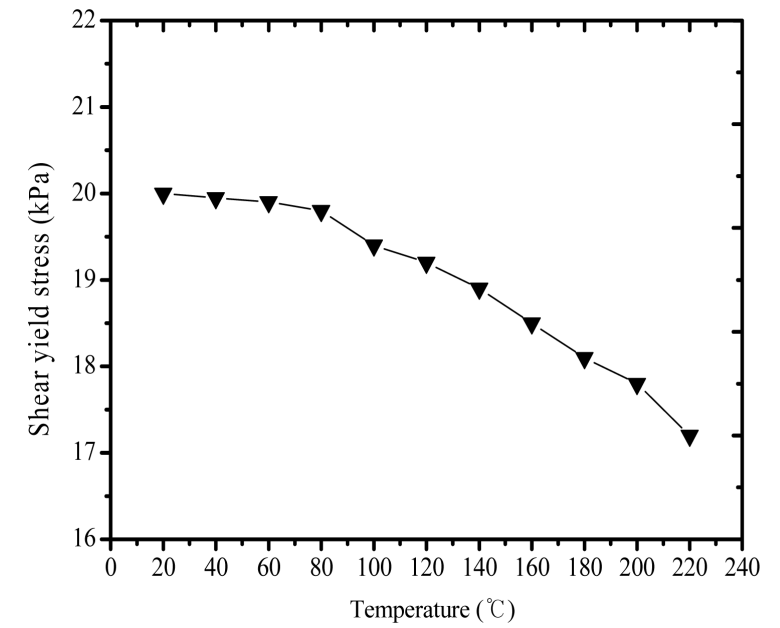

(a) Effect of application temperature on shear yield stress

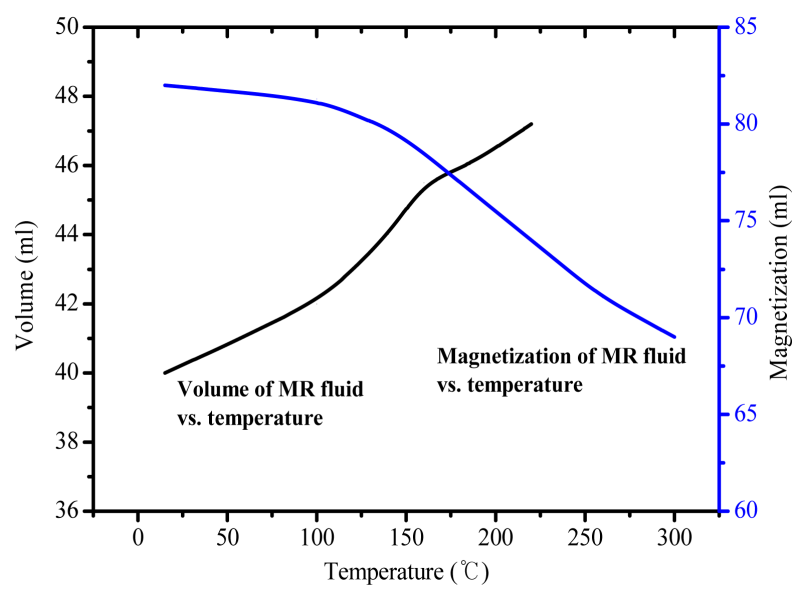

(b) Effect of temperature on volume and magnetization

Fig. 6. (Color online) Effect of temperature.

$\mathrm{emu} / \mathrm{g}$ and $97 \mathrm{emu} / \mathrm{g}$ respectively, and the difference is about $7 \%$, which is not distinct.

\subsection{Different application temperatures}

The working temperature of MR fluid rises from $20^{\circ} \mathrm{C}$ to $220^{\circ} \mathrm{C}$ by adjusting shear yield stress instrument shown in Fig. 2, and the influence rule of application temperature on shear yield stress is obtained in Fig. 6(a), and Fig. 6(b) shows the effect of temperature on volume and magnetization of MR fluid. Where the mass fraction of MR fluid is $66.9 \%$, the magnetic field is $0.2 \mathrm{~T}$.

It is clearly observed that the shear yield stress decreases about $15 \%$ with the rising of application temperature from $20^{\circ} \mathrm{C}$ to $220^{\circ} \mathrm{C}$ and reduces deeply as the temperature is higher than $100^{\circ} \mathrm{C}$. The phenomena can be explained by Fig. 6(b), which shows the volume and magnetization variation of MR fluid with application temperature. According to the curve of volume vs. temperature, the volume expand ratio caused by temperature rise can reach

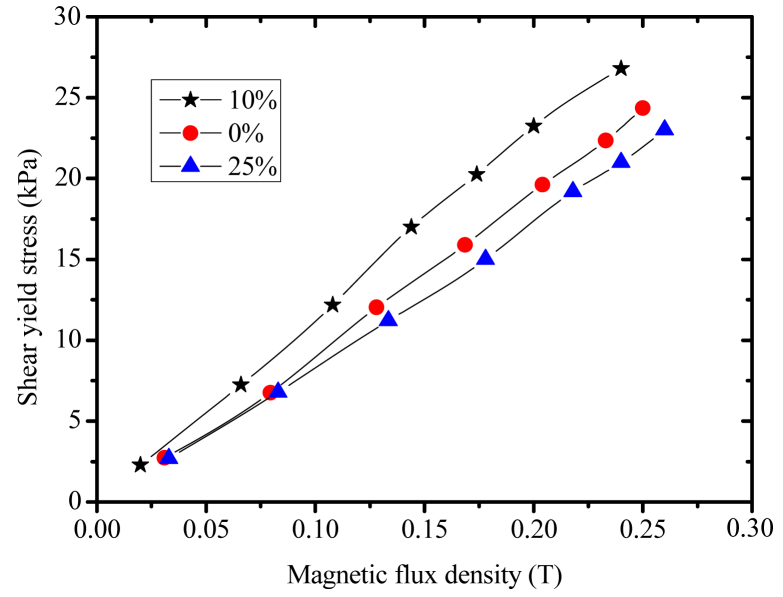

Fig. 7. (Color online) Effect of nanoparticles.

to $20 \%$, which leads to the reduction of the volume of MR fluid in working gap and further weakens the shear yield stress. However, because of the separation of silicone oil from MR fluid partly, the influence capacity of volume expand on shear yield stress may be weakened. According to the curve of magnetization vs. temperature, the magnetization decreases about $10.2 \%$ with the increasing of application temperature from $20^{\circ} \mathrm{C}$ to $220^{\circ} \mathrm{C}$.

\subsection{Adding of nanoparticles}

In this experiment, the $10.0 \mathrm{~g}$ and $30.0 \mathrm{~g}$ nanoparticles are added into the MR fluid with mass fraction of $66.9 \%$ respectively, and the mass fraction of nanoparticles is $10 \%$ and $25 \%$ (volume fraction is $3.25 \%$ and $9.17 \%$ ), the corresponding shear yield stress of prepared MR fluid is shown in Fig. 7.

It is observed that the MR fluid with $10 \%$ mass fraction of nanoparticles has higher shear yield stress because of the formation of more regular chains due to nanoparticles. Increasing the mass fraction of nanoparticles, the shear yield stress can't be enhanced constantly. While the mass fraction is $25 \%$, the shear yield stress even decreases, the reason is that much more nanoparticles adsorb at the surface of micro-particle, which increases the distance between the micro-particles, and therefore, reduce the rheological effect of MR fluid. Such a conclusion can be drawn that the shear yield stress can not be enhanced with the increasing of mass fraction constantly.

\section{Conclusions}

The shear yield stress of MR fluids with different particle mass fractions, particle sizes, application temperatures and the adding of nanoparticles are measured respectively, and the corresponding influence rules are also obtained. 
The experiments indicate that the above factors have all certain effect on the shear yield stress of MR fluid. Shear yield stress increases approximate linearly with the mass fraction because of the enhancement of magnetization. Particle size can also improve the shear yield stress and the $7.0 \mu \mathrm{m}$ particles increase by $20 \%$ than that of $2.5 \mu \mathrm{m}$ particles. The adding of $10 \%$ mass fraction nanoparticles can increase the yield stress, while increasing the content of nanoparticles, the shear yield stress even decreases due to thickness wrapping of nanoparticles. When the application temperature changes from $20^{\circ} \mathrm{C}$ to $220^{\circ} \mathrm{C}$, the shear yield stress decreases by $15 \%$ because of the thermal expansion and the thermal magnetization effect.

\section{Acknowledgment}

The support of National Natural Science Foundation of China (No. 51405488, 51575512) the Postdoctoral Science Foundation of China and Jiangsu Province (No. 2013M541754 and 1302074C) and the Top-notch Academic Programs Project of Jiangsu Higher Education Institutions in carrying out this research are gratefully acknowledged.

\section{References}

[1] S. R. Agustin, F. Donado, and R. E. Rubio, J. Magn. Magn. Mater. 335, 149 (2013).

[2] Y. H. Huang, Y. H. Jiang, X. B. Yang, and R. Z. Xu, J.
Magn. 20, 317 (2015).

[3] H. J. Kim, G. C. Kim, G. S. Lee, T. M. Hong, and H. J. Choi, J. Nanosci. Nanotechno, 13, 6005 (2013).

[4] Z. Z. Tian, F. Chen, and D. M. Wang, J. Intell. Mater. Syst. Struct. 25, 1937 (2014).

[5] O. Erol, B. Gonenc, D. Senkal, S. Alkan, and H. Gurocak, J. Intell. Mater. Syst. Struct. 23, 427 (2012).

[6] G. A. Ewijk, G. J. Vroege, and A. P. Philipse, J. Magn. Magn. Mater. 201, 31 (1999).

[7] X. B. Yang, Y. H. Jiang, Y. H. Huang, R. Z. Xu, H. G. Piao, G. M. Jia, and X. Y. Tan, J. Magn. 19, 345 (2014).

[8] Z. Z. Tian, F. Chen, and D. M. Wang, J. Intell. Mater. Syst. Struct. 26, 414 (2015).

[9] M. Ashtiani, S. H. Hashemabadi, and A. Ghaffari, J. Magn. Magn. Mater. 374, 716 (2015).

[10] X. Tang and H. Conrad, J. Phys. D Appl. Phys. 33, 3026 (2000).

[11] J. M. Ginder, L. C. Davis, and L. D. Elie, Int. J. Mod. Phys. B 10, 3293 (1996).

[12] J. M. Ginder and L. C. Davis, Appl. Phys. Lett. 65, 3410 (1994).

[13] Y. M. Han, S. Kim, J. W. Kang, and S. B. Choi, Smart Mater. Struct. 24, 115016 (2015).

[14] A. Spaggiari and, E. Dragoni, J. Intell. Mater. Syst. Struct. 26, 1764 (2015).

[15] D. M. Wang, B. Zi, Y. Zeng, Y. F. Hou, and Q. R. Meng, J. Mater. Sci. 49, 8459 (2014).

[16] H. Sahin, X. Wang, and F. Gordaninejad, J. Intell. Mater. Syst. Struct. 20, 2215 (2009). 